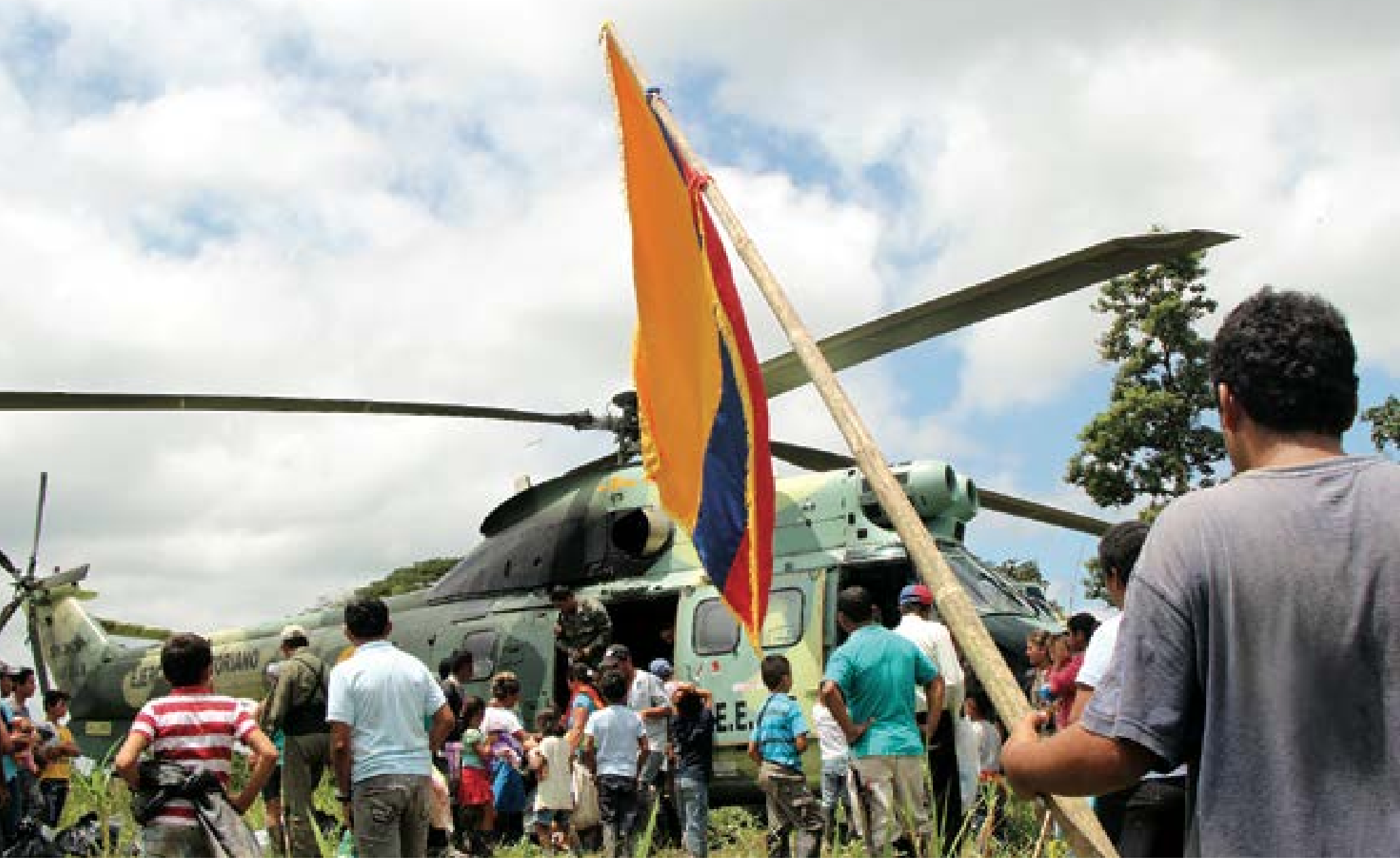

\title{
LOS CAMBIOS GEOPOLÍTICOS, SOCIALES Y CULTURALES Y SU INFLUENCIA EN LAS FUERZAS ARMADAS DEL ECUADOR
}

Profesor, Daniel Granda Arciniega, PhD

Quito, 17-II-2019

\section{RESUMEN}

En este artículo, analizaremos la posición de las fuerzas sociales y políticas de frente a los cambios militares, sociales y culturales, que provienen de las condiciones endógenas de la sociedad, pero también de condiciones internacionales y su influencia en las Fuerzas Armadas del Ecuador. En una primera parte, analizaremos las condiciones geopolíticas mundiales y la bipolaridad y su influencia en las Fuerzas Armadas del Ecuador. En una segunda parte, analizaremos la Declaración de los Derechos del Hombre de primera, segunda, tercera y cuarta generación y sus efectos en las Fuerzas Armas del Ecuador.

Palabras claves: Cambio. Estado. Sociedad. Fuerzas Armadas. Guerra. Guerra fría. Política. Geopolítica. Revolución. Contra-revolución. Seguridad Nacional. Derechos Humanos. Indígenas. Mujeres. Clase Media. Reformismo.

\section{ABSTRACT}

In this article, we will analyze the position of social political forces facing the military, social and cultural changes, which come from the endogenous conditions of society, but also from international conditions and their influence in the Armed Forces of Ecuador. In the first part, we will analyze the word geopolitical conditions and bipolarity and its influence in the Armed Forces of Ecuador. In a second part, we will analyze the Universal Declaration of Human Rights, of the first, second, third and fourth generations and its effects on the Armed Forces of Ecuador.

Keywords: Change. State. Society. Armed Force. War. Cold War. Politics. Geopolitics. Revolution. Counterrevolution. National Security. Indigenous. Women. Middle Class. Reformism. 


\section{Introducción}

La derrota del nazismo y del proyecto hitleriano para Europa y el mundo, por las fuerzas aliadas de Europa y Estados Unidos, dejó a los vencedores en condiciones de administrar el triunfo y con grandes posibilidades de crecimiento, de conformidad con sus renovados proyectos políticos, económicos y militares. Por un lado, Estados Unidos y Europa, bajo el sistema capitalista. Por otro lado, la Unión de Repúblicas Socialistas Soviéticas, bajo el sistema comunista, a la rusa.

La URSS, rápidamente emprendió un proceso de crecimiento económico, en base de la planificación centralizada y se encaminó a una expansión ideológica, política y territorial en Europa Oriental, Asia, África y América Latina, bajo una concepción estalinista.

Estados Unidos, por su parte, percibió en el sistema político soviético un proyecto expansionista en lo ideológico, político, socio-económico y militar, frente a lo cual elaboró una teoría con sus variaciones en el espacio y en el tiempo: el mundo, después de la segunda guerra mundial, continúa, con otros actores y en posiciones diferentes, en guerra total y permanente: La URSS vs EE.UU.

América Latina, en la primera mitad del siglo XX, sufre problemas territoriales entre varios Estados; la mayoría de países viven en condiciones de dependencia de Estados Unidos, con economías extractivistas de algunos minerales y en algunos casos, con monoproductos agrícolas de exportación; la organización socio económica es casi feudal; y los sistemas políticos son producto de las élites, sin participación democrática del pueblo. En estas circunstancias surgen fuerzas políticas que buscan un cambio de la estructura económica, de las relaciones sociales y del sistema político, que cree nuevas y mejores condiciones para su desarrollo. En esta lucha por el cambio, América Latina se encuentra bajo una división geopolítica mundial, atravesada por la bipolaridad del mundo: Estados Unidos, que cree que América Latina es su área de influencia natural, y por lo tanto, quiere mantener las cosas como están, asume la posición del anti-cambio, y posteriormente de un cambio moderado. La Unión Soviética y más tarde China, aunque lejanas, que representan la posibilidad del cambio y que atraen a las fuerzas que se ubican en esa dirección.

En este artículo, analizaremos la posición de las fuerzas sociales y políticas de frente a los cambios militares, sociales y culturales, que provienen de las condiciones endógenas de la sociedad, pero también de condiciones internacionales y su influencia en las Fuerzas Armadas del Ecuador. En una primera parte, analizaremos las condiciones geopolíticas mundiales y la bipolaridad y su influencia en las Fuerzas Armadas del Ecuador. En una segunda parte, analizaremos la
Declaración de los Derechos del Hombre de primera, segunda, tercera y cuarta generación y sus efectos en las Fuerzas Armas del Ecuador.

\section{Los cambios geopolíticos mundiales y sus efectos en las fuerzas armadas de américa latina}

\section{A. La teoría de Clausewitz y sus variaciones}

Podríamos decir que hasta la segunda guerra mundial, los Estados manejaron la teoría de Clausewitz sobre la guerra, como una concepción válida. "La guerra es continuación de la política por otros medios."(Clausewitz, 1956, p. 30). La guerra, bajo ésta concepción era un hecho armado de un Estado contra otro Estado. Para manejar la guerra, como enfrentamiento del Estado soberano con otro Estado soberano, el Estado organizó un ejército preparado para la guerra. En este aforismo de Clausewitz existen cuatro conceptos importantes:

1.- La Guerra. La guerra, como un hecho de violencia entre dos ejércitos de dos Estados diferentes. Para Clausewitz, "la guerra es un acto de fuerza para obligar al contrario al cumplimiento de nuestra voluntad." (1956, p. 12). El fin es destruir al enemigo y conquistar sus riquezas y recursos económicos como mecanismo para destruir su voluntad de lucha. La guerra, en cuanto tiene un fin claro y preciso, no sólo es un acto de voluntad apasionada, sino un acto racional de cálculo, de oportunidad y de precisión, en el tiempo y en el espacio. La guerra es la aplicación de estrategias y tácticas bélicas, racionalmente planificadas. La guerra es el uso de la fuerza para doblegar la voluntad del enemigo e imponer la propia voluntad. El objetivo de la guerra es alcanzar la victoria, con los medios violentos necesarios.

2.- La continuación. Una vez doblegada la voluntad de luchar del adversario, debido a la firme presencia de fuerzas y la reconocida capacidad de su destrucción, se crean condiciones para pasar a un acto de negociación política, es decir, la vuelta a la política, como mecanismo racional para manejar los conflictos. Durante el tiempo de la guerra hubo acción violenta de uso de las armas; pero también existió manejo político, en las presencias y ausencias de la fuerza en uno u otro lado del territorio del enemigo. Por esta razón, Clausewitz, dice que la guerra es "continuación de la política, con otros medios." En consecuencia, la guerra es un acto violento y hasta irracional, pero al mismo tiempo es racional y busca condiciones para la paz. Podríamos decir que existe una relación dialéctica entre la paz y la guerra, y entre la guerra y la paz. 
La paz conlleva elementos de la guerra, y la guerra conlleva elementos de la paz. Desde este punto de vista, y considerando las condiciones reales del comportamiento del ser humano, es comprensible el aforismo de Clausewitz. También se puede entender la guerra, dentro de la concepción de Clausewitz, como una continuación, una prolongación de la política interna de un Estado, hacia la guerra exterior. Esta posición garantizaría de mejor forma el manejo y respaldo de la población en el frente interno y el comportamiento en el frente externo.

3.- La Política. La política, como capacidad racional para manejar, controlar y resolver conflictos, es una actividad fundamentalmente de la autoridad estatal, dentro del territorio nacional. Para el manejo de conflictos se sirve de los medios legales, con la fuerza proporcional de la policía, con la participación de los jueces y utilizando las cárceles como mecanismos de castigo a las personas que han infringido la ley y han alterado el orden. La política para Clausewitz y para el pensamiento político moderno es la capacidad legal y legítima, que la autoridad estatal utiliza para resolver los conflictos internos de la nación. La política es la capacidad de la autoridad legítima de negociación y de integración de los diversos sectores de la sociedad, considerando el bien común. La política es un compromiso para hacer prevalecer el bien común.

4.- Los Medios. Está claro que Clausewitz concibe como medios diferentes a los utilizados por la política para conocer y resolver los conflictos internos, que son medios racionales de negociación, de solidaridad y de persuasión, de aplicación de la ley y de utilización de las cárceles como mecanismo de aislamiento a una persona peligrosa para la sociedad. Y en la cárcel, incluso, buscar mecanismos de reeducación, rehabilitación y de reinserción en la sociedad. En ningún caso, un conciudadano puede ser considerado como un enemigo, sino como una persona que ha violado, por varios motivos, una $\mathrm{u}$ otra ley y que merece ser juzgado y castigado por medio de las sentencias de los jueces. Jamás se puede planificar, desde la política, la muerte de un conciudadano. Por el contrario, en la guerra, sí existe el enemigo y los medios son muy diferentes, son armas de destrucción y de muerte al enemigo y entre más mortíferas mejor. En la guerra prevalece el uso de la fuerza violenta, con clara intención de destruir al enemigo, caso contrario, el enemigo elimina al otro, y se apodera de sus recursos. En la política se utiliza los medios racionales de negociación y persuasión; mientras que en la guerra se usa los medios violentos de la fuerza.
Este aforismo de Clausewitz, después de la segunda guerra mundial y con el uso de la bomba atómica, ha sufrido algunas variaciones:

a. La presencia de la bomba atómica ha cambiado las relaciones de los ejércitos en guerra. La utilización de la bomba atómica en Hiroshima, tuvo su planificación, pero fue de destrucción total. Las guerras eran pensadas para apropiarse de los recursos de la parte derrotada. Con la bomba atómica no queda nada, ni fisca, ni humanamente. Una guerra con la bomba atómica provoca tal nivel de destrucción que no quedan recursos del enemigo para que el triunfador pueda beneficiarse; $y$ tampoco quedan personas a las cuales se pueda doblegar su voluntad y someterlas a la voluntad del vencedor. Este tipo de guerra al perder toda racionalidad y convertirse en un acto de destrucción total, no tiene nada de continuación de la política; no tiene nada de política, sino de anti-política. La teoría de Clausewitz ya no sería aplicable para el caso de una guerra atómica; manteniendo su validez para casos de guerra localizada en países sin bomba atómica. Esta variación, se desprende de la teoría de la guerra total de Ludendorff, publicada en su libro, La guerra total en 1935. Con la experiencia de la primera guerra mundial, Ludendorff, plantea que lo que está en juego en la guerra es la sobrevivencia de la comunidad racial. Por lo tanto, hay que preparar a la población para que defienda su historia y su destino como identidad comunitaria, de frente a otra comunidad que busca lo mismo. Desde este punto de vista, la política se pone al servicio de la guerra y se involucra toda la población a la guerra. Se requiere, según Ludendorff, una estrecha relación entre el trabajador y el soldado, el primero para producir lo que el soldado requiere para actuar en la guerra. Todo está al servicio de la guerra. Por eso, la guerra total, exige un involucramiento de toda la comunidad, consciente de lo que está en riesgo es su sobrevivencia como identidad histórica. En la guerra total el objetivo es destruir totalmente al enemigo. (Ludendorff, 1964)

b. La presencia de fuerzas revolucionarios internas con apoyo de sectores importantes de la población y con apoyo internacional, que en algunos casos, se trató de una evidente intención de exportar procesos revolucionarios y de sometimiento de pueblos a la influencia de una potencia mundial. En los procesos revolucionarios reaparece el concepto de enemigo en el interior de la nación, frente al cual, las Fuerzas Armadas reaccionan violentamente 
en defensa del status quo, en una clara reacción contra-revolucionaria.

c. La existencia del crimen organizado a nivel internacional, que en base del narcotráfico, ha formado verdaderas fuerzas paramilitares ilegales y con respaldo de sectores de la población, que han visto en esta actividad, la forma de salir de la pobreza, o de enriquecerse rápidamente. Esta organización criminal actúa en red con fuerzas transnacionales y busca permanentemente penetra en las instituciones del Estado, como la policía, los jueces, los militares y la política. Frente al crimen organizado a nivel internacional, las Fuerzas Armadas organizan fuerzas operativas conjuntas, con la limitante de tener que actuar en el territorio de otro Estado. Para esto se requiere de una sistemática colaboración entre Fuerzas Armadas de varios países, lo cual complica las operaciones militares.

d. El aforismo de Clausewitz, ha sufrido una complementariedad con los estudios de Foucault, que pone el ejemplo de la construcción del poder. La constitución del poder, según la teoría contractualista del siglo XVII y XVIII se realiza a través de una operación contractual, racional. En la teoría marxista no surge por ahí el poder, sino como resultado de una "funcionalidad económica", que proviene de la lucha de clases. El poder político, o el Estado, surge como consecuencia de la lucha de clases, y por tanto es un problema de carácter económico. Estas dos teorías se podrían sintetizar diciendo que el poder que una persona posee, lo cede, por contrato o por la fuerza. "El poder es una relación de fuerza... el poder es esencialmente lo que reprime... el poder es la guerra, proseguida por otros medios. $\mathrm{Y}$ en ese momento invertimos la proposición de Clausewitz y diríamos que la política es la continuación de la guerra por otros medios." (Foucault, p. 28). Foucault que no está desarrollando el tema del poder, sino como un ejemplo de la lucha entre los saberes sometidos y los saberes científicos, plantea una concepción de la política como ejercicio de la fuerza que reprime, como una guerra. En consecuencia, destruye todas las premisas de Clausewitz, en el sentido de que este autor diferenció la política de la guerra, por el tipo de conflicto y por las partes en conflicto, es decir, la política para el interior del Estado, y la guerra para el exterior del Estado. Foucault, sin esta preocupación, y tomando la política como un hecho de fuerza, invierte el aforismo de Clausewitz y plantea que "la política es la continuación de la guerra por otros medios." Esta inversión de la propuesta de Clausewitz quiere decir, según Foucault tres cosas:
- Las relaciones de poder se expresan, en un momento determinado, en la guerra. "Si bien es cierto que el poder político, dice Foucault, detiene la guerra, hace reinar o intenta hacer reinar una paz en la sociedad civil, no lo hace en absoluto para neutralizar los efectos de aquella o los desequilibrios que se manifestó en su batalla final. En esta hipótesis, el papel del poder político sería reinscribir perpetuamente esa relación de fuerza, por medio de una especie de guerra silenciosa, y reinscribirla en las instituciones, en las desigualdades económicas, en el lenguaje, hasta en los cuerpos de uno y otros." (Foucault, p. 29). Para Foucault, el Estado ejerce el poder a través de las instituciones, de las relaciones económicas, en el lenguaje, en las expresiones culturales, bajo una especie de "guerra silenciosa" en contra de los ciudadanos, con lo cual mantiene el orden y una aparente situación de paz relativa. Según Foucault, la soberanía es el gran concepto que sirve de paraguas para la creación del sujeto, de la unidad del poder y de la propia ley. Para el ejercicio del poder político se han formado "aparatos de poder" sectorizados, que conforman estructuras de poder, con diversas estrategias y tácticas de poder, que permiten, a los "operadores de poder", el ejercicio del poder, en verdaderas "relaciones de dominación, de fuerza, de guerra." (Foucault, p. 51). Ante el peligro de confundir relaciones de poder con relaciones de guerra, Foucault aclara diciendo: "Lo tomaré simplemente como un (caso) extremo, en la medida en que la guerra puede considerarse como el punto de tensión máximo, la desnudez misma de las relaciones de fuerza." (Foucault, p. 52). Por debajo de las relaciones de poder que ejerce la autoridad a través de las instituciones, Foucault ve relaciones de fuerza y por tanto, de guerra. Esto explica la inversión del aforismo de Clausewitz: "La política es la continuación de la guerra por otros medios." (Foucault, p. 53). El aforismo de Clausewitz se explica, según Foucault, desde el punto de vista histórico, desde cuando el Estado moderno logró centralizar el poder; asumió la tarea de librar la guerra; se apropió de los instrumentos bélicos; es decir, desde cuando estatizó la guerra. Desde entonces, creó un aparato militar, profesional y técnico para manejar la guerra, y este es el origen de los ejércitos modernos. Con este proceso de monopolización de la fuerza física por parte del Estado, se eliminó la guerra cotidiana, la guerra privada. (Foucault, p. 53). Foucault dice que esto ocurrió "tras el final de las guerras civiles y religiosas del siglo XVI.” (Foucault, p. 54). Con estas consideraciones, Foucault, plantea que la guerra no sólo que fue el origen del Estado, de la ley y de la paz, sino que subsiste debajo de todos ellos. "Así pues, estamos en guerra unos contra otros; un frente de batalla atraviesa toda la 


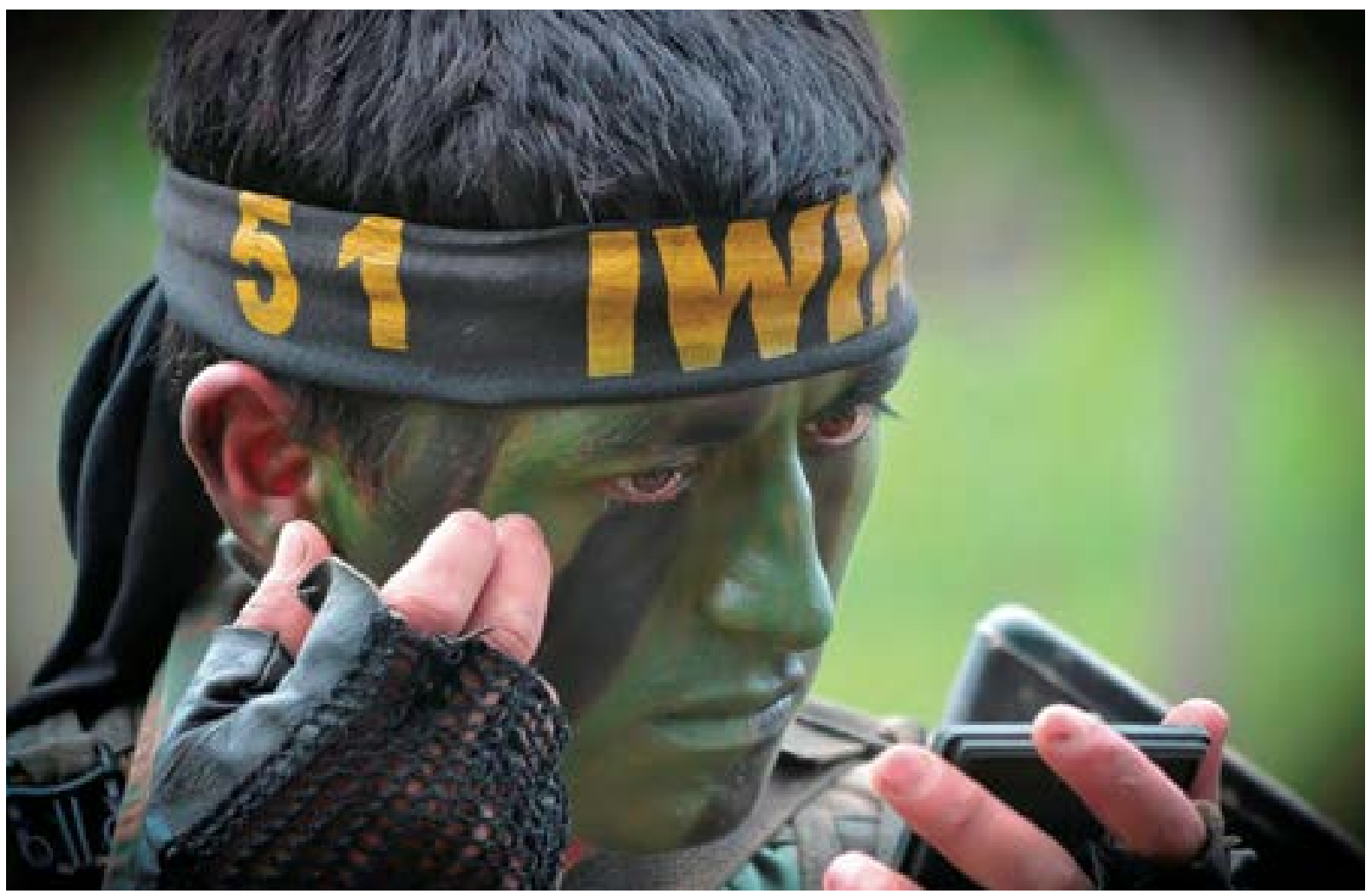

Soldado Iwia de nacionalidad Shuar. Fuente: Archivo fotográfico OPSIC - Ejército Ecuatoriano.

sociedad, continua y permanentemente, y sitúa a cada uno en un campo o en el otro. No hay sujeto neutral. Siempre se es, forzosamente, el adversario de alguien." (Foucault, p. 56). Para Foucault, la guerra ha terminado $\mathrm{y}$ ha sido suficientemente racionalizada para quien se cree el vencedor. Pero la guerra continúa para quien ha sido derrotado: "no podemos poner término a la guerra con una reconciliación o una pacificación, sino únicamente en la medida en que seamos efectivamente los vencedores." (Foucault, p. 56). Desde este punto de vista, Clausewitz, con su aforismo lo que intentó es separar la política de la guerra, aunque mantuvo un nivel de continuidad, al decir con "medios" diferentes. En la política están presentes relaciones de poder, de dominación y por tanto, situaciones de guerra; y en la guerra hay consideraciones de las condiciones del enemigo, de los fines y por tanto, de la política.

- Dentro de la aparente paz relativa, las relaciones de poder y la lucha por el poder, deben interpretarse como "secuelas de la guerra." Según Foucault, las relaciones en la sociedad civil, permitidas por el Estado, son efectos de la guerra; y la propia imposición de las decisiones de la autoridad a través de las instituciones son mecanismos de la "guerra silenciosa."

- La decisión final en los conflictos internos es, según Foucault, un hecho de fuerza, donde las armas se expresan a través de los jueces. Foucault ve en la teoría contractualista la relación contrato/opresión, y en la teoría marxista la relación guerra/represión. En las relaciones de poder, que impone el poder político, lo que existe son relaciones belicosas.

También en este contexto se explica la propuesta de Foucault que, basado en el estudio del comportamiento real del Estado con la sociedad civil, tanto en su origen, como en la actualidad y sobre todo en el manejo de la dominación y represión, invierte la proposición de Clausewitz y dice que: "la política es la continuación de la guerra por otros medios." Para Foucault, el Estado realiza una "guerra silenciosa", tiene "aparatos de poder", "operadores de poder", ejerce un "poder disciplinario" con lo cual mantiene el orden y una paz relativa. Cuando Foucault habla de "guerra silenciosa" hace una diferencia con la guerra clara y abierta. Es decir, según Foucault existiría una guerra silenciosa y una guerra en cuanto tal. Esto quiere decir que la política es la continuación de la guerra por otros medios, pero de una guerra en forma silenciosa. La política además, no solo es el resultado de la relación contrato/opresión, como dirían los contractualistas, sino el resultado de la relación dominación/opresión. (Foucault, 2010, pp. 28ss).

\section{B. De "El eslabón más débil" a la guerra revolucionaria}

La teoría de Clausewitz sobre la guerra y sus variaciones, nos permiten comprender mejor los acontecimientos históricos de la segunda mitad del 
siglo XX y los inicios del siglo XXI y sus efectos en las Fuerzas Armadas de América Latina y en particular del Ecuador. Hannah Arendt, reclama el hecho de que no se le preste suficiente interés a la violencia como mecanismo para el cambio histórico. "La segunda guerra mundial no fue seguida por la paz sino por una guerra fría y por el establecimiento del complejo militar-industrial-laboral." (Arendt, 1999, pp. 116ss)

La URSS, como actor principal de la derrota del nazismo, aprovechó su condición de país victorioso para avanzar lo más posible en los países de Europa Oriental. Sólo se detuvo cuando encontró una fuerte resistencia, tanto de los propios países europeos, como de los Estados Unidos. En estas circunstancias cambió de dirección y se dirigió a los países del tercer mundo y bajo sistemas coloniales. Inició el apoyo a los movimientos de liberación nacional. Con esta nueva estrategia se trataba de seguir rompiendo "eslabones más débiles”. (Mires, Fernando, 2005, p. 241). Lenin, en la crítica del imperialismo, plantea: "Lo esencial en la crítica del imperialismo es saber si es posible reformar la base del imperialismo, si hay que avanzar con el objeto de agudizar y ahondar aún más las contradicciones que éste engendra, o si hay que retroceder con el objeto de atenuar esas contradicciones." (Lenin, 1970, p. 408). El imperialismo, según Lenin, genera explotación de los países en el mundo y en muchos lugares se agudizarán más las contradicciones que en otros. De aquí que hay eslabones de la cadena imperialista, donde surgirán con mejores oportunidades los movimientos de liberación nacional. "La creación de un Estado nacional único como instrumento de libertad económica y cultural. Este movimiento por la independencia nacional amenaza al capital europeo en sus zonas de explotación más valiosas y promisorias, y el capital europeo sólo puede conservar su dominación aumentando continuamente sus fuerzas militares". (Lenin, 1970, p. 419). Para Lenin, a mayor opresión de los países colonialistas, mayor resistencia de las colonias. Para Lenin, una característica del imperialismo es su expansión territorial, creando una cadena controlada por monopolios y por el capital financiero. En esta cadena imperialista existen eslabones, donde se agudizan más las contradicciones, es allí donde se debe apoyar los movimientos de liberación nacional, para convertirlos en una guerra revolucionaria, con el propósito de romper los eslabones del imperialismo. Esta posición de Lenin, asumida como política oficial por la URSS, le creó muchas simpatías entre los intelectuales y las fuerzas revolucionarias en los países en proceso de liberación nacional. Con esta nueva circunstancia, el espacio de enfrentamiento se desplazó de Europa a los países del "Tercer Mundo". En estos países tendría lugar la Guerra Fría, con claros actores y posiciones: El escenario geopolítico mundial de mediados del siglo XX era: La URSS apoyando a las fuerzas del cambio; los EE.UU. defendiendo sus áreas de influencia y el status quo colonial de muchas metrópolis europeas en decadencia. El proyecto revolucionario soviético recogió todas las expresiones de rebeldía social y política, a las cuales les dio organicidad y dirección política. (Arón Raymond, 1967). "Desde 1940 a 1980, durante la era de la descolonización, mientras los antiguos imperios restituían o conferían, en unos pocos años, la independencia a territorios que durante varios siglos habían subordinado a su autoridad, la Unión Soviética, mediante una progresión inversa, se apropiaba por la astucia y la fuerza de una multitud de países extranjeros." (Revel, Jean-Francois, 1983, p. 59). Arendt, estudiando el tema de la violencia, y con clara actitud crítica contra la URSS, dice: "Identificar a los movimientos de liberación nacional con tales estallidos (de violencia) es profetizar su ruina. Pensar que existe algo semejante a una "Unidad del Tercer Mundo", al cual pueda dirigirse en nuevo slogan de la era de la descolonización "Nativos de todos los países subdesarrollados uníos" (Sartre) es repetir las peores ilusiones de Marx." (Arendt, 1999, p. 128).

En China, el Partido Comunista Ruso, apoyó inicialmente a Chiang Kaishek para llegar al poder, (1927) luego éste traicionó a Moscú y se entregó a las burguesías europeas. El Partido Comunista Ruso fue derrotado, pero no el comunismo, que retornará más tarde apoyando a Mao Tse Tung, en contra de Chiang Kaishek. ${ }^{1}$ En China, Mao Tse Tung, con el apoyo soviético que acababa de anunciar la posesión de la bomba atómica, lograba una gran victoria frente a Chiang Kai-Sheck, en 1949, frente a lo cual los EE.UU. que evitaba una guerra atómico localizada, hizo muy poco para evitar la caída de China bajo la influencia soviética. Esta influencia soviética en China durará poco tiempo no por la intervención norteamericana, sino por la propia dinámica China, que planteará la construcción de su propio proyecto político y de la expansión del mismo hacia los países colonizados y subdesarrollados.

Distinta fue la reacción de EE.UU. en el caso de Corea, donde decidió exitosamente detener el expansionismo soviético en el sur de Corea. Con esto se aplicaba la doctrina Truman, de la contención, en contra de la posición de MacArthur, comandante del teatro de operaciones, que creía que se debía continuar la guerra hasta destruir al enemigo. La administración Truman

\footnotetext{
1 Ver la extraordinaria novela de André Malraux, La Condición Humana, 1982, Editorial Sudamericana, Barcelona, donde el autor, demuestra que en el proceso revolucionario chino, de 1927, se manifiesta la verdadera condición humana, llena de pasiones, odios, ambiciones, muerte, voluntad, alegría, solidaridad y amor, en medio de conflictos de intereses políticos, geopolíticos, económicos, de partidos políticos, Estados, banqueros, inversionistas y constructores internacionales.
} 
creía que eso sería "pelear la guerra equivocada, en el lugar equivocado, en el momento equivocado, y contra el enemigo equivocado." Kissinger, 2015, p. 295). En el escenario de Asia actuaron las dos superpotencias: La URSS y Estados Unidos, con sus propios intereses y sus propias lógicas. EE.UU. mantendrá en la guerra fría, una posición ambivalente, como dice Henry Kissinger. Sin embargo, ya en la guerra de Corea, bajo la dirección de Kim Il Sung y sus propios intereses, se jugaban intereses de la URSS y de EE.UU. y de China, a quién los rusos veían con mucha preocupación. (Kissinger, 2015, pp. 291ss). En el caso de Corea, se aplica la teoría de Clausewitz, donde la guerra y la paz, son momentos distintos de la política. La fuerza era necesaria para producir condiciones de negociación. La guerra en Corea terminó en un empate, pero con un gran perdedor que fue la URSS, como dice Kissinger.

Los conflictos internos en la zona europea de influencia soviética llevaron al planteamiento de la "coexistencia pacífica", que significa la no intervención por parte de las potencias mundiales en las zonas de influencia, en caso de conflictos internos. La tesis de la coexistencia pacífica soviética, fue aceptada por EE.UU, porque coincidía con la teoría Truman de la contención. De la coexistencia pacífica soviética y de la teoría de la contención norteamericana, resultaba una situación hibrida que fue llamada por el articulista Walter Lippmann: “The cold war". (Mires, p. 250).

Entre la coexistencia pacífica y la contención, Estados Unidos, mantuvo posiciones diversas, en el caso de Cuba en 1959 y en medio de contradicciones, Kennedy se resignó, inicialmente, a perder Cuba y aceptar su vinculación al bloque soviético, excluyéndola del programa de apoyo para el desarrollo económico social para América latina, Alianza para el Progreso. La URSS, bajo un cálculo equivocado de la posición de EE.UU., instaló cohetes atómicos en la isla. La posición de Kennedy varió y se radicalizó, cuando constató la existencia de dichos cohetes atómicos en la isla. El cambió consistió en la decisión de asumir el riesgo de un conflicto atómico en contra de la URSS, en un espacio muy cercano al territorio norteamericano. Las negociaciones llegaron al punto de exigir a la URSS el retiro de dichos cohetes atómicos de la isla a cambio de otras acciones similares de EE.UU en Turquía. "El retiro de los cohetes de Cuba fue el comienzo del fin de la lenta derrota que iba a experimentar la URSS en la guerra del Tercer Mundo.” (Mires, p. 257)

Estados Unidos, en el intento de evitar la expansión soviética en América Latina y para evitar la reproducción del caso cubano, creó la doctrina de la seguridad nacional, como una respuesta a la ideología marxista del comunismo internacional. Con la doctrina de la seguridad nacional, EE.UU. inició una nueva intervención en los distintos Estados de América
Latina, a tal punto de programar y apoyar algunas dictaduras militares. El caso de Chile es muy claro, con el apoyo a Pinochet y la caída de Allende en 1973. Esta política norteamericana despertó un gran rechazo en el conjunto de las fuerzas progresistas de la región y por tanto, un antinorteamericanismo.

La doctrina de seguridad nacional fue muy difundida y su aceptación generó muchos cambios en los Fuerzas Armadas de América Latina. Sin embargo, es necesario diferenciar la posición de algunos países como los del cono sur, con una población con un porcentaje alto de migración europea y con mandos que provenían de la alta burguesía, se aceptó las intervenciones norteamericanas con todos sus excesos. Hay que tomar en cuenta que en estos países las inversiones de EE.UU. y de Europa eran muy grandes y los industriales, inversionistas y banqueros, no estaban dispuestos a dejar perder sus zonas de influencia. En estos países, además, se adoptó la teoría de K. Schmitt, que concibe la política como la relación amigo-enemigo. Los militares gobernantes estaban convencidos que la guerra contra-revolucionaria era contra un enemigo interno al cual había que destruir, aunque éste sea su compatriota. (Schmitt, C., 1998, p. 56. Comblin, 1978, p. 59). Por otra parte, los países andinos, especialmente Ecuador y Perú, donde las presiones norteamericanas fueron recibidos con más moderación y con espíritu crítico por parte de las propias Fuerzas Armadas. En Ecuador y Perú tuvo más aceptación el programa del Presidente Kennedy de Alianza para el Progreso, a la luz del cual se realizaron en Ecuador, algunas reformas importantes, como la reforma agraria. Esta diferencia se entiende debido a la existencia en el mundo andino de una sociedad más atrasada, con estructuras sociales cerradas, represivas y autoritarias, razón por la cual existían sectores en las Fuerzas Armadas comprometidos con el cambio, dada su procedencia de sectores medios provincianos, populares, con muchas ansias de ascenso social y económico. Muchos de ellos provenientes de militares de tropa. En Ecuador, no se aceptó la teoría de Schmitt, de considerar la política como la relación amigo/enemigo, porque los militares provenían de los mismos sectores poblacionales de los que protestaban. Los rebeldes y protestantes eran sus parientes, sus paisanos provincianos, vecinos o conocidos. Además, la preocupación fundamental en la década del sesenta y setenta fue la planificación de la guerra, ante una eventual invasión peruana, provocada por las autoridades políticas peruanas. El Ecuador mantenía el conflicto con el Perú, debido a lo inejecutable del Protocolo de Rio de Janeiro de 1942 en la zona del río Cenepa. En estas condiciones lo que menos le interesaba al Ejército ecuatoriano es involucrarse en una guerra contra-revolucionaria interna. El presidente Fujimori, y su asesor Montesinos, en el contexto de una campaña electoral por la reelección a la Presidencia de la República, acusado 
por el diplomático y político, candidato Javier Pérez de Cuéllar, de no defender el territorio peruano, y en su afán de desviar la atención de los graves conflictos internos, inició una progresiva invasión a territorio ecuatoriano. El Ecuador se había preparado para evitar que sucedan pérdidas territoriales, como en anteriores ocasiones. Se adquirió, un moderno material bélico; se actualizó la teoría de la guerra; se aprobó una nueva estructura institucional; se organizó los teatros de operaciones; se preparó la moral del soldado para cumplir la misión de defender la integridad territorial; y se fortalecieron las relaciones con la población civil, sobre todo con los periodistas, medios de comunicación y organizaciones populares. El momento llegó y en enero de 1995, todos unidos, el frente político, social y económico, actuaron coordinadamente, para que el Ejército Ecuatoriano, con excelentes generales y coroneles, y muy bien profesionalizado, logre una victoria militar, frente al Ejército Peruano. El Presidente de la República, Sixto Durán Ballén, lideró la dirección política de la guerra, bajo la consigna, que toda la población la acogió: "Ni un paso atrás". En este momento confluyeron grandes líderes militares, un gran país unido, y una causa justa. Al cumplirse 24 años de este acto heroico de las Fuerzas Armadas del Ecuador, donde los líderes militares estuvieron a la altura de los acontecimientos, rendimos homenaje al Ejército victorioso del Alto Cenepa. Con esta guerra y con un Ejército Ecuatoriano victorioso, se crearon las condiciones, como diría Clausewitz, para regresar a la política y llegar a un Acuerdo de Paz, firmado por el presidente del Ecuador Jamil Mahuad, y por el presidente del Perú Alberto Fujimori, el 26 de octubre de 1998, en Itamaraty, Brasilia, del cual hablaremos en otra ocasión. En consecuencia, los ecuatorianos hemos aprendido que la paz no se logra sólo con buena voluntad propia y peor con buena voluntad ajena.

Es en EE.UU donde se sistematizó la concepción sobre la guerra revolucionaria y adoptada por algunas Fuerzas Armadas de América Latina, en forma mecánica. Se concibió la guerra revolucionaria como la nueva estrategia del comunismo internacional, proveniente de Moscú y China. Los norteamericanos creyeron que los rusos y luego los chinos han concebido la victoria del socialismo a través del tercer mundo. La guerra revolucionaria fue asimilada a la guerra de liberación nacional, a la guerrilla subversiva, al terrorismo, como fases diferentes de un solo proceso. La guerra revolucionaria, como nueva técnica de la guerra, consistía en vincularse con la población, la cual por sus condiciones de pobreza y de marginalidad estaba en condiciones de unirse al proceso revolucionario. La población colaboraría con la revolución porque estaba en muy malas condiciones y que no podía perder nada, porque ya lo tenía todo perdido. De aquí que la población más apta para la vinculación al proceso revolucionario era la población rural y posteriormente, se pensó en la población urbano-marginal. El problema que surgió, era que si en el campo existía más población indígena o campesinos. Este fue un problema que la izquierda no comprendió claramente, sobre todo, en la región andina. El problema fue si el sujeto revolucionario, a más de la clase obrera poco desarrollada, era el indio, el campesino o el mestizo. Los planteamientos fueron distintos para el caso de Bolivia, Perú, Ecuador y México. (Svampa Maristella, 2016, pp. 29ss).

De frente a esta concepción de la guerra revolucionaria se construyó la teoría de la contrarevolución. Se trataba de entender la técnica revolucionaria para hacer contra-técnicas adecuadas. Una de las principales estrategias fue aislar la población indígena, campesina y mestiza de los brotes revolucionarios. Para esto se implementó programas de integración de indígenas, campesinos y mestizos. Para identificar los miembros activos de la subversión y la posible población colaboradora con la revolución se desarrolló la especialidad de inteligencia militar, con lo cual se obtenía información necesaria para la toma de medidas necesarias. La inteligencia, como especialidad militar, es una de las acciones principales de la guerra contra-revolucionaria, igual que la acción psicológica, para lo cual se desarrolló la acción cívico-militar. El objetivo era demostrar que el gobierno es más eficaz que la revolución. Las Fuerzas Armadas de Ecuador y Perú creyeron que muchos cambios eran necesarios, y por tanto, se involucraron en los mismos, en algunos casos como protagonistas principales y dispuestos a alianzas con organizaciones de izquierda. La política de atractivos y de soborno de EE.UU. con formación, equipo y tecnología, si bien atrajo a los militares ecuatorianos, no significó una entrega incondicional. Esto explica el diferente carácter de las dictaduras del cono sur y las dictaduras de Ecuador y Perú de la década del 60 y 70. En las Fuerzas Armadas de Ecuador prevaleció una posición reformista, con lo cual se evitó la revolución. En Ecuador, las Fuerzas Armadas estuvieron más marcadas por los factores de la historia nacional, razón por la cual, adoptó una posición nacionalista. Mientras que en las Fuerzas Armadas de los países del Cono Sur, prevaleció la concepción de combatir la revolución con la contra-revolución. Cuando el Estado no puede responder adecuadamente a la presión sobre el cambio, recurre a la represión. En el caso de los países andinos, durante las dictaduras militares, se llevó a cabo la reforma y la represión; a diferencia de los países del cono sur que respondieron, prioritariamente, con represión. (Granda, Daniel, 2018, ibid. Ver el interesante libro de Hobsbawn E.J. 1978, p. 267-268). Además, los partidos comunistas y socialistas de Ecuador no han sido radicalmente revolucionarios, sino más bien reformistas. El radicalismo no hubiese encontrado el respaldo de la mayoría de la población. Tanto en tiempos de dictadura, como de democracia demostraron un gran oportunismo y claras tendencias a 
favor del populismo concentrador de poder, autoritario y corrupto, que, luego del fin de la guerra fría, los llevó a unirse a Abdalá Bucaram, Gutiérrez y Correa, manifestando, muchos de ellos, en el ejercicio del poder, mediocridad, ineficacia y corrupción.

La teoría leninista, recogida por la política internacional de la URSS, de apoyar para que se rompa el sistema por "el eslabón más débil", es decir, para lograr ubicar a los países del tercer mundo bajo la influencia soviética, fracasó, gracias a la propia reacción de dichos países, a los errores de la URSS, y a la política de los Estados Unidos. En la década del 80, la URSS estaba muy debilitada tanto en su frente externo, como en el frente interno, y el 9 de noviembre de 1989 cae el muro de Berlín, que significa la caída de la URSS, o del socialismo real. Con la caída de uno de los actores de la bipolaridad, de una de las superpotencias, se podría pensar que llegamos al fin de las luchas revolucionarias y de la geopolítica bipolar, y de la guerra fría y sus consecuencias. La guerra fría la ganó Estados Unidos, que permanece como la superpotencia. Chomsky, en 1991 y con espíritu crítico contra Washington, afirma que la política de EE.UU. "exageró" las intenciones y la capacidad soviética y las utilizó como pretexto para su política de contención y su expansionismo mundial e intervencionismo en el mundo, en nombre de la libertad y de la democracia. "Pero, en la actualidad, el enemigo se ha retirado, de modo que tal vez podamos satisfacer nuestro "deseo de no implicarnos" en los asuntos de los demás." (Chomsky, Noam, 2003, p. 27). Chomsky en este libro intenta demostrar que Estados Unidos sobredimensionó la amenaza soviética, para esconder el carácter expansionista e intervencionista del capitalismo norteamericano, en búsqueda de territorio, de materias primas y sobre todo de petróleo. Desaparecida la "supuesta amenaza soviética", y continuando con las mismas prácticas intervencionistas por parte de los Estados Unidos, Chomsky concluye: "En consecuencia, se hace necesario reconocer que el verdadero enemigo es el propio Tercer Mundo." (Chomsky, 2003, p. 54). Según Chomsky el verdadero enemigo de la política estadounidense es la posición nacionalista y reformista de los gobernantes y para combatirla era necesario trabajar con policías y militar para pasar de la "defensa hemisférica" a la "seguridad interna": "La principal amenaza para los intereses de los EE.UU. la plantean los "regímenes nacionalistas" que son receptivos de las presiones populares para la "mejora inmediata de los bajos niveles de vida de las masas" y a la diversificación de las economías." (Chomsky, 2003, p. 77). En consecuencia, según Chomsky, 1989, con la caída del muro de Berlín, no significa el fin de la guerra fría, sino el replanteamiento de una guerra que continuará, bajo otros pretextos, que logren justificar el intervencionismo norteamericano. "la guerra fría está a medio acabar. Este fin aparente es una elaboración ideológica más que un hecho histórico." (Chomsky, 2003, 9. 91). En consecuencia, ni mucho menos se trataba del fin de la historia, como lo planteó, erróneamente, Fukuyama, en su libro, El fin de la Historia, 1992. Por efectos de las acciones u omisiones, de los protagonistas principales de la guerra fría y de otros actores mundiales, 12 años más tarde, se produjo otro acontecimiento, que marcó un nuevo escenario de guerra mundial: la caída de las torres gemelas de Nueva York, el 11 de noviembre del 2001. El terrorismo será el nuevo problema mundial, que dividirá al mundo entre los terroristas y sus aliados directos o indirectos y los países que luchan en contra del terrorismo. Al terrorismo se unirá el narcotráfico internacional.

\section{Los cambios socio-económicos y culturales y sus efectos en las fuerzas armadas del ecuador}

\section{A. Los derechos humanos, individuales, económico-sociales y culturales}

Mientras la historia real enfrentaba a hombres, ideologías, religiones, partidos políticos, Estados, y ejércitos, para dividir el mundo en una geopolítica bipolar; el esfuerzo por racionalizar las acciones de los hombres y de los Estados, se expresaba en la reflexión sobre el origen, el estado natural y el estado de derecho, en el cual debe vivir el hombre. Mientras pensadores y militares pensaban y planificaban la política, la guerra y la ubicación en un reparto geopolítico del mundo; filósofos se preocupaban por el origen, el desarrollo y el destino del hombre. Mientras algunos hombres perfeccionaban las estrategias y las tácticas de la guerra; otros, descubrían la solidaridad humana y formulaban los derechos humanos del hombre. La filosofía reflexionaba sobre la política, a la luz de los acontecimientos reales. La razón combatía contra la astucia de la razón, como diría Hegel. La razón luchaba contra el asalto a la razón, que significó el fascismo, como dice Lukács (Lukács, Georg, 1972).

Ante esta dualidad de pensamiento y de acción, $\mathrm{y}$ ante la tragedia del ser humano del siglo XX, producto de su historia real, era necesario que, en nombre de la sobrevivencia de la humanidad, la razón y la reflexión, resurjan para el bien de la humanidad. Del abismo que se había producido entre la política y la filosofía, era necesario, en nombre de la sobrevivencia del hombre, una reconciliación de la razón práctica, con la razón pura, como diría Kant. Era necesario tomar consciencia que en la reflexión filosófica del hombre existe una clara dimensión de la política, y que por tanto, era posible, hacer prevalecer la política a la guerra en las relaciones humanas, tal como diría el propio Clausewitz.

A este esfuerzo reflexivo, que recoge la realidad y también la dignidad del ser humano, responde la historia de los derechos humanos, como producto del quehacer humano y no de ninguna fuerza extra- 


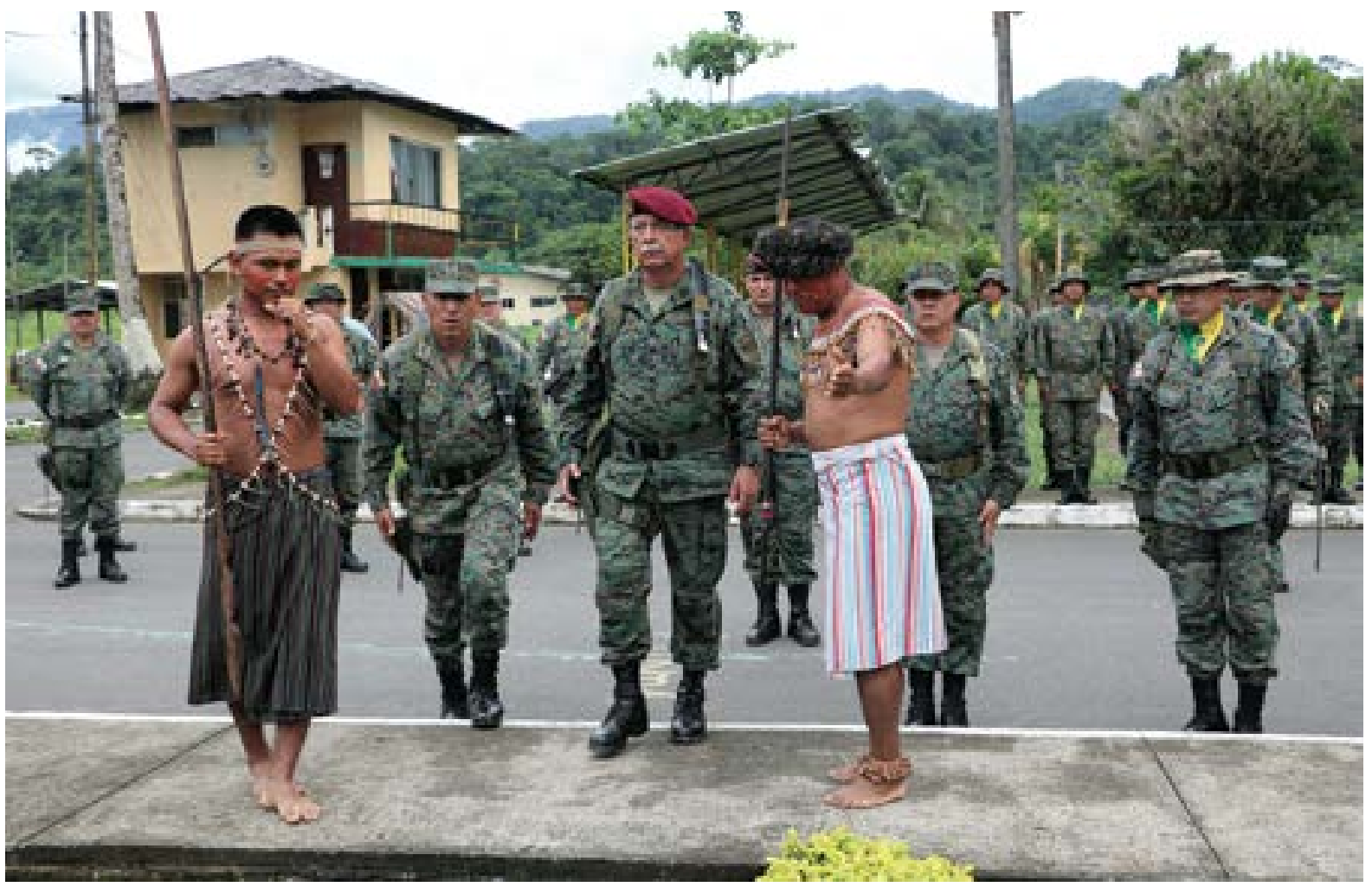

Visita del señor GRAD Roque Moreira a las comunidades del Oriente Ecuatoriano.

Fuente: Archivo fotográfico OPSIC - Ejército Ecuatoriano.

histórica. En la tradición judeo-cristiana, de inspiración religiosa, se resalta el valor de la vida en cada persona y el derecho a protegerla. Lutero, plantea que es el individuo el que se salva o se condena de frente a Dios. Lutero, insiste en la soledad del individuo, sólo de frente a Dios, sólo de frente a Cristo, sólo de frente a la escritura. (Weber, Max, 1977, pp. 41ss). Es en la modernidad que se reconoce el valor de la persona humana en cuanto "valor fuente" de todos los valores sociales y por lo tanto, fundamento último del orden jurídico. (Lafer, Celso, 1994, p. 35). La modernidad, insiste en el individuo, como el sujeto de los derechos. La Declaración de los Derechos del Hombre, en 1789, recoge los derechos naturales e inalienables de las personas para que puedan exigir su respeto a los demás y a la propia organización política, el Estado. El Estado, no surge como evolución natural, sino que es el resultado del ejercicio del derecho individual de las personas, incluso para auto obligarse a obedecer. El Estado, en la concepción jusnaturalista, es producto del contrato social. El Estado surge para proteger $\mathrm{y}$ garantizar los derechos inherentes al individuo y considerados como derechos naturales. El Art. 2 de la Declaración Universal de los Derechos el Hombre y del Ciudadano de 1789, dice: "La finalidad de toda asociación política es la conservación de los derechos naturales e imprescriptibles del hombre. Tales derechos son la libertad, la propiedad, la seguridad y la resistencia a la opresión." Por esto se los reconoce como los derechos de primera generación. El Art. 16 de la misma Declaración, dice: "Toda sociedad en la cual no esté establecido la garantía de los derechos, ni determinada la separación de los poderes, carece de Constitución". De esta manera, el hombre, que ya no confiaba en el derecho divino, ni natural, lograba conquistar sus derechos a través de un contrato social. Estos derechos de primera generación limitan el poder del Estado de frente a los derechos del individuo. Los derechos humanos son "aquellas exigencias que brotan de la propia condición natural de la persona humana, y que, por ende, reclaman su reconocimiento, su respeto e incluso su tutela y promoción por parte de todos; pero especialmente de quiénes estén constituidos en autoridad.” (Vergés, Ramírez, 1997, p. 16)

Los derechos de segunda generación, producto también del aporte del socialismo, son aquellos que, basados en el derecho individual, para su defensa, sobre todo en la población más vulnerable, requieren de una organización social y política, como un sindicato, un partido o un colectivo en general. Para el derecho al trabajo, la salud, la educación, la vivienda, de la población vulnerable, el Estado asume la responsabilidad, en nombre de la colectividad. De estos derechos se desprende también el derecho de reunión, de asociación, de opinión, y de huelga. Estos derechos de segunda generación, al contrario de los derechos de primera generación, exigen más solidaridad social y amplían los poderes del Estado. De aquí que para mayor comprensión y tratamiento, los Organismos Internacionales, han dividido los derechos humanos, en derechos civiles y políticos y derechos económico- 
sociales y culturales. (Lafer, 1994, p. 149).

Los derechos de tercera y cuarta generación, ya no tienen al individuo como el titular de los derechos, sino a grupos humanos, como la familia, el pueblo, la nación, colectividades regionales o étnicas, la humanidad y la naturaleza. De aquí se desprende, entre otros, el derecho a la autodeterminación de los pueblos consagrada en la Carta de las Naciones Unidas, (Resolución 1514 (XV) de la Asamblea General, diciembre de 1960), que coincide con los procesos de liberación nacional de varios países de sus antiguas metrópolis colonialistas. Aquí el titular del derecho es una colectividad. En el mismo sentido, los pueblos reclaman el derecho al desarrollo y la construcción de un nuevo orden económico internacional. El derecho a la paz; el derecho al medio ambiente sano; el derecho a los fondos oceánicos como patrimonio de la humanidad, que ha culminado con la aprobación de la CONVEMAR por la mayoría de Estados del mundo. El derecho a la autodeterminación de los pueblos, no significa que, en una unidad histórica, se tenga el derecho a la secesión o al separatismo y división de Estados. El espíritu de este derecho está dirigido a la liberación de los pueblos con respecto a los países colonialistas.

Los derechos, de primera, segunda, tercera y cuarta generación, debidamente positivados son el resultado de la lucha de los individuos y de los pueblos por su sobrevivencia y por su desarrollo y han sido la base para las luchas de reivindicaciones sociales, económicas, culturales y políticas. Los Estados han sido presionados para asumir como atribución principal la protección de los derechos humanos de sus connacionales. Los organismos internacionales, igualmente, en forma complementaria, han asumido el deber de velar por el respeto de los derechos humanos. Las distintas declaraciones de los Derechos Humanos, en diferentes momentos históricos han servido como instrumentos de cambio, que asumidos por la lucha de los pueblos, han transformado la realidad económica, social, cultural y política de los pueblos. El cambio que se ha producido, apelando a los derechos del hombre, es extraordinario y ha afectado a todas las sociedades, Estados e instituciones a nivel mundial.

\section{B. Los Derechos Humanos y el cambio en las Fuerzas Armadas del Ecuador}

El reconocimiento y la promoción de los derechos humanos, como hemos visto, también nos vienen de Europa y Estados Unidos, pero que recogen realidades de todas las partes del mundo. De aquí la importancia de mantener una posición prudente y crítica, ya que si recogemos y aplicamos, mecánicamente, una u otra doctrina, corremos el riesgo de que en las metrópolis se cambie $\mathrm{y}$ nos quedamos en posiciones que ya no las aplican ni sus propios creadores. Por ejemplo, el Presidente Carter de EE.UU. (1976-1980), "sin apartarse un centímetro de la doctrina Truman, se propuso, al levantar la política internacional de los derechos humanos, dotar al mundo occidental de una ideología que enjuiciara al comunismo no sólo desde una perspectiva geopolítica, sino que cuestionara a la vez el orden político interno de los países enemigos." (Mires, p. 273). Con la política de defensa de los derechos humanos, Carter, no sólo que cuestionaba el frente interno de la URSS, sino también las propias dictaduras militares que EE.UU. había apoyado en América Latina. En la defensa de los derechos humanos, Carter coincidió con muchos movimientos de izquierda que luchaban por la democracia y en contra de las dictaduras militares. En coherencia con esta posición, Carter, firmó con Panamá el acuerdo, por el cual EE.UU. devolvería a Panamá el Canal el $1 \mathrm{~d}$ enero del 2000; luego se encarcelaría y se lo expatriaría a EE.UU. a uno de sus principales aliados, el dictador, Noriega. Igualmente, no defendió a Somoza, expresión de la corrupción, frente al movimiento sandinista, donde estaba el partido comunista y el apoyo cubano. Carter, difundió la política de defensa de los derechos humanos en todo el mundo, desenmascarando y debilitando al enemigo, e incluso a sus aliados del cono sur. Las dictaduras en su más clara expresión represiva, anti derechos humanos, debían terminar y dar paso a la democracia. El llamado Documento de Santa Fe, no entendió la estrategia ideológica del Presidente Carter, y exigía a los EE.UU. ser más leal con sus aliados dictadores de América Latina, aunque éstos sean autoritarios y violadores de los derechos humanos de sus pueblos. (Documento, Comité de Santa Fe, 1982, pp. 19-68)

Ante los cambios producidos entre los países más poderosos, que pueden llegar a macro-acuerdos entre ellos, y dejar sin fundamento, muchas posiciones radicales de los países periféricos, es necesario una posición más reflexiva y prudente, para evitar precisamente estos cambios traumáticos, como los producidos en Chile, Argentina y en todo el cono sur. Hoy podemos decir, que la posición crítica y prudente de las Fuerzas Armadas del Ecuador ante la imposición de la doctrina de seguridad nacional, fue la más correcta y evitó situaciones trágicas de persecución y muerte de compatriotas. Se evitó la generalización de la violencia y por el contrario se adoptaron políticas de integración con los distintos sectores de la población. Incluso, Ecuador fue el primero en anunciar su retorno a la democracia en 1976, antes que muchos países de América Latina. En el caso ecuatoriano, desde inicios del 70 en la Academia de Guerra del Ejército se invitaron a prestigiosos académicos con estudios en el exterior, con clara posición en defensa de los derechos humanos, como Gonzalo Abad Ortiz, el exjesuita Luis Eladio Proaño, que introdujeron la cátedra de Sociología; y a finales del 70 a Daniel Granda Arciniega, que introdujo la cátedra de Ciencias 
Políticas, y otros intelectuales que también fueron parte del Instituto de Altos Estudios Nacionales. En este Instituto se debatían, criticaban y proponían cambios importantes a la doctrina de seguridad nacional. Se insistía más en el desarrollo que en la seguridad. La seguridad es desarrollo y sin desarrollo no hay seguridad. La seguridad es un efecto del desarrollo. El desarrollo es el progreso económico, social y político. De esta manera, en Ecuador, el desarrollo entró en la doctrina de la seguridad nacional, con más fuerza. En la Constitución de 1979, el planteamiento sobre el desarrollo se institucionalizó y se creó el CONADE, como ente responsable de la planificación nacional, presidido por el vicepresidente de la República, el CONADE. (Moncayo, Patricio, 2017). La lealtad de las Fuerzas Armadas, no era con una persona o una clase en el poder, sino con el pueblo, la República, el Estado y la Nación. (Hobsbawm, 1978, p. 252). Esta situación explica la posición de la dictadura militar en el Ecuador, tanto en la década del 60, como en la década del 70. La doctrina de la seguridad nacional de Estados Unidos fue aceptada con espíritu crítico y sin los radicalismos de la posición de las Fuerzas Armadas del cono sur. (Granda, Daniel, 2018, pp. 22ss). La teoría de la subordinación de los militares al poder civil, ha funcionado en forma relativa, aunque para finales del siglo XX, la subordinación ha sido más firme, a pesar de los excesos del poder civil. En democracia, el ejército se sintió bien con gobiernos reformistas, aceptó los gobiernos conservadores, reaccionó negativamente frente al populismo corrupto de Bucaram, rechazó la firma de tratados internacionales inconsultos y la entrega del gobierno al sector bancario, y se mantuvo con una resistencia pasiva de frente al populismo autoritario de Correa. Algunos militares en servicio pasivo en democracia han actuado en política, mayoritariamente y en forma exitosa, con posiciones reformistas y bajo concepciones socialdemócratas, acompañados de fuerzas de izquierda y de centro.

Las tesis del cambio económico, social, cultural y político, no le eran extrañas a la institución militar, por el contrario, habían diagnosticado, claramente la sociedad ecuatoriana y coincidían en muchos planteamientos de cambio con los sectores involucrados de la sociedad. Esta posición no era una sorpresa ni para la derecha, ni izquierda ecuatorianas. Es obvio, que también hubo sectores retrógrados que se oponían a todo planteamiento de cambio, pero fueron minoritarios $\mathrm{y}$, sobre todo, no marcaron la dirección institucional. Sectores que defendían más radicalmente la doctrina de la seguridad nacional y a la política norteamericana y de la derecha ecuatoriana. Es claro que hubieron palomas y halcones; blandos y duros; moderados y radicales, pero predominaron los moderados y reflexivos, que coincidían con la necesidad de los cambios. También han existido posiciones reaccionarias y de persecución a los dirigentes políticos de izquierda y de protesta social, pero han sido aisladas, focalizadas y temporales, más no sistemáticas y permanentes. La reacción negativa, que en ocasiones, se ve en las Fuerzas Armadas sobre los derechos humanos, en verdad no es contra los derechos humanos en sí, sino en contra de la instrumentalización de los derechos humanos por parte de ciertas organizaciones internacionales y nacionales, en beneficio de otros objetivos.

En tiempos de la dictadura del 60 y 70 , en un claro reconocimiento y protección de los derechos de los pueblos indígenas, se inició un trabajo sistemático con la población indígena, respetando su lengua, su cultura, su educación, y su religión. El ejército se convirtió en la institución que facilitó el ingreso de la población indígena a sus filas, no sólo por convicción de integración, sinotambién por las ventajas en la seguridad, sobre todo del oriente ecuatoriano. Igualmente, la Policía Nacional ha integrado a su Institución a gran parte de la población indígena masculina y femenina. Posteriormente, las universidades abrieron sus puertas a la población indígena. Con esto, se realizó un cambio extraordinario con la población indígena, que se los reconoció en calidad de ciudadanos, como condición previa al reconocimiento de sus derechos. En las instituciones se reconoce la igualdad de los seres humanos. Con el acceso a la esfera de lo público se tiene acceso a la igualdad. Las diferencias quedan para el ámbito privado. Según Hannah Arendt, el primer derecho humano es el derecho a tener derechos. Es decir, el derecho de tener ciudadanía. La ciudadanía es el derecho a tener derechos. (Lafer, 1994)

Las Fuerzas Armadas del Ecuador, reconociendo y aceptando los derechos de la mujer a participar en la vida institucional, aceptaron recibir a mujeres para la formación de oficiales y tropa. Si bien el respeto y vigencia de este derecho puede crear en la práctica algunos problemas, lo importante es el reconocimiento de este derecho y el aporte que las mujeres pueden dar a la institución.

Se comenzó a ejecutar planes en forestación, en el tratamiento del cauce de ríos y en defensa de los manglares, en clara defensa de la naturaleza, para combatir el deterioro del medio ambiente.

Las Fuerzas Armadas del Ecuador, no pusieron ningún reparo a la Carta de Conducta de Riobamba de 1980, luego conocida como Doctrina Roldós: "El respeto a los derechos humanos constituye norma fundamental de la conducta interna de los Estados y su defensa es una obligación internacional, por lo que la acción conjunta ejercida en protección de estos derechos no viola el principio de la no intervención." Esta declaración, que en una concepción radical de la doctrina de seguridad nacional, hubiese sido inaceptable por parte de las fuerzas Armadas, en 
Ecuador, no generó ningún problema entre el frente político y el frente militar. El reconocimiento y respeto de los derechos humanos replanteaba el concepto de soberanía nacional.

Las Fuerzas Armadas del Ecuador, sensibles a los derechos humanos de las personas, en la década del 70 y 80, no tuvieron una política institucional de rechazo a la inmigración de la población chilena, argentina y uruguaya que vino masivamente al Ecuador, producto de la represión militar en el cono sur. Por el contrario, aceptaron que en muchos casos se trató de una inmigración positiva, sobre todo para las universidades, donde se integraron muchos, en calidad de exiliados y refugiados. De esta manera, el Estado ecuatoriano reconoció el derecho al refugio y el derecho al trabajo de muchas personas que vinieron del cono sur, producto de una visión geopolítica bipolar. La guerra fría produjo muchos refugiados de Cuba, Chile, Argentina y de otros países.

Por mucho tiempo en Ecuador se ha mantenido una conducta de comprensión con la protesta social, la desobediencia civil y la resistencia, hasta que en la Constitución del 2008, Art. 98, se reconoció como un "derecho de los individuos y colectivos, frente a acciones u omisiones del poder público". Según Rawls, El problema que le ocupa a Locke es el de formular el derecho a la resistencia a la Corona al amparo de una Constitución mixta. (Rawls, John, 2009, p. 165). Para Locke, el fin de cualquier ley "no es abolir ni restringir la libertad, sino preservarla y ensancharla." En base de este principio Locke fundamenta el derecho a la resistencia y a la desobediencia. El derecho a la resistencia es consecuencia de una crisis en el Estado. "Quien ejerciendo autoridad se excede del poder que le fue otorgado por la ley, y se sirve de la fuerza que tiene al mando suyo para cargar sobre sus súbditos obligaciones que la ley no establece, deja, por ello mismo, de ser un magistrado, y se le puede ofrecer resistencia, lo mismo que a cualquiera que atropella por la fuerza el derecho de otro." (Locke, 1973, N 202, p. 154) El Art. 2 de la Declaración de los Derechos del Hombre de 1789, reconoce el derecho a la resistencia a la opresión. Los hombres tienen el derecho de no dejarse oprimir por los gobernantes. Defensa de la libertad y soberanía popular. Existe el principio de la reciprocidad tanto del gobernante; como del gobernado: Si el gobernante exige ser obedecido, el gobernado exige ser gobernado sabiamente y por leyes justas. (Faver, 1994, p. 214). Las Fuerzas Armadas del Ecuador, por provenir de los sectores medios y populares, y por conocer la historia de los gobernantes, han comprendido muy bien que, en muchos casos, existen claros motivos objetivos para que el pueblo indígena, campesino, y sectores urbanos, hagan uso del derecho a la resistencia, por lo cual han sido más prudentes en sus reacciones de represión y han evitado crear más violencia a la ya existente. Además, conocen muy bien que el pueblo indígena por mucho tiempo ha ejercido la resistencia pasiva. Esto no quiere decir, que no ha existido violencia, en forma aislada, que produjo muertes como el caso de Aztra, del dirigente político Abdón Calderón Muñoz, y de algunos dirigentes indígenas y populares.

Esta actitud a favor del cambio en las Fuerzas Armadas condujo a una posición reformista, como alternativa a la revolución y a la doctrina de la seguridad nacional. Posición que institucionalizada y en ocasiones, convertida en política estatal, que con recursos económicos provenientes del petróleo, ha producido cambios importantes en la sociedad y Estado ecuatorianos. El cambio ha transitado de la sociedad a la institución y de la institución a la sociedad. La población ecuatoriana ha cambiado en los últimos 60 años en forma significativa: ha cambiado en la composición y densidad poblacional y hoy tenemos una población más mestiza y diversa, producto de una gran movilidad social. Se ha convertido en una población más citadina que rural, Quito y Guayaquil se acercan a los 3 millones de habitantes, cada una. Ha dejado de ser una sociedad cerrada y se ha convertido en una sociedad abierta e interconectada. La población ecuatoriana tiene más prácticas democráticas, en la familia, la escuela y en las relaciones sociales y políticas. Los derechos de los indios, mujeres y población vulnerable han sido reconocidos y protegidos por el Estado. La clase media ha crecido con sus niveles económicos, sociales y culturales. (Hurtado, Osvaldo, 2017, pp. 153-203). Esta actitud favorable al cambio de las Fuerzas Armadas del Ecuador, le permite no solo comprender correctamente su pasado, sino, y sobre todo, responder a la pregunta: ¿Qué hacer ahora? Actuar en el presente, y planificar el futuro, para garantizar la integridad territorial, con profesionalismo y con la actitud favorable al cambio, al progreso y al desarrollo integral, evitando imposiciones internas o externas, fuera de una posición crítica y reflexiva, en beneficio de los intereses de la nación. 


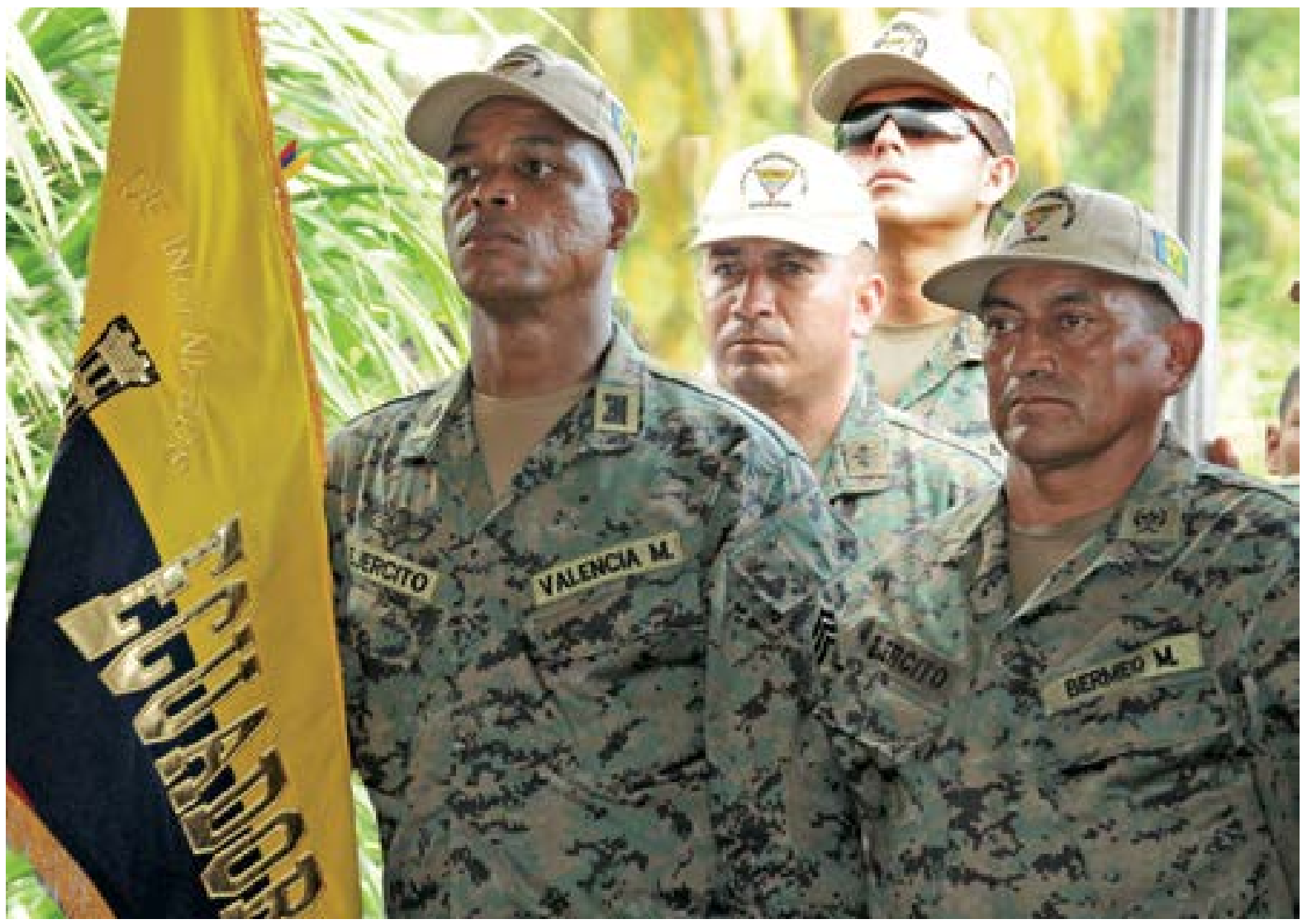

Diversidad de etnias y culturas que conforman al Ejército Ecuatoriano.

Fuente: Archivo fotográfico OPSIC - Ejército Ecuatoriano.

\section{REFERENCIAS}

[1] Arendt, Hannah, Crisis de la República, 1.999, TAURUS, España

[2] Aron, Raymond, El opio de los intelectuales, 1967, Ediciones siglo XX, Buenos Aires

[3] Clausewitz, Karl, La Guerra, 1956, Editorial Quito, Quito

[4] Comblin, Joseph, El poder militar en América Latina, 1978, Ediciones Sígueme, Salamanca

[5] Chomsky, Noam, El miedo a la democracia, 2003, Crítica, Barcelona

[6] Documento, Santa Fe, en, Varios, La guerra total. La política exterior de Ronald Reagan, 1982, Editorial El Conejo, Quito

[7] Foucault, Michel, Defender la sociedad. Curso en el Colegio de Francia (1975-1976), 2010, Fondo de Cultura Económica, México

[8] Fukuyama, Francis, El fin de la historia y el último hombre, Segunda reimpresión, 1993, Editorial Planeta, Colombia.

[9] Granda, Daniel, La profesión militar en la era del conocimiento, en, Revista de la Academia de Guerra del Ejército Ecuatoriano, 2018
[10] Hobsbawm, E. J., Revolucionarios. Ensayos contemporáneos, 1978, ARIEL, Barcelona

[11] Hurtado, Osvaldo, Ecuador entre dos siglos, DEBATE, Colombia.

[12] Kissinger, Henry, Orden mundial. Reflexiones sobre el carácter de las naciones y el curso de la historia, 2015, DEBATE, Barcelona

[13] Lafer, Celso, La reconstrucción de los derechos humanos. Un diálogo con el pensamiento de Hannah Arendt, 1994, Fondo de Cultura Económica, México

[14] Lenin, V.I., El imperialismo, etapa superior del capitalismo, en, Obras Completas, Tomo XXIII, 1970 , Editorial Cartago, Buenos Aires

[15] Locke, John, Ensayo sobre el gobierno civil. 1973, Aguilar, Madrid

[16] Ludendorff, Erik von, La guerra total, 1964, Pleamar, Buenos Aires

[17] Lukács, Georg, El asalto a la razón. La trayectoria del irracionalismo desde Schelling hasta Hitler, 1972, Ediciones Grijalbo, Barcelona

[18] Malraux, André, La Condición Humana, 1982, Editorial Sudamericana, Barcelona
[19] Mires, Fernando, El orden del caos. Historia del fin del comunismo, 2005 , Editorial Nueva Sociedad, Buenos Aires

[20] Moncayo, Patricio, La planificación estatal en el interjuego entre desarrollo y democracia, 2017, FLACSO, Quito

[21] Rawls, John, Lecciones sobre la historia de la Filosofía Política, 2009, Paidós, Barcelona

[22] Revel, Jean-Francois, Cómo terminan las democracias, 1983, Editorial Planeta, Barcelona

[23] Schmitt, Carl, El concepto de lo político, 1998, Alianza Editorial, Madrid

[24] Svampa, Maristella, Debates latinoamericanos. Indianismo, desarrollo y populismo, 2016, Edición Edhasa, Buenos Aires

[25] Vergés, Ramírez, Salvador, Derechos Humanos: Fundamentación, 1997, TECNOS, Madrid

[26] Weber, Max, La ética protestante y el espíritu del capitalismo, 1977, Ediciones Península, Barcelona. 